\title{
Evaluation, management and outcome of upper urinary tract transitional cell carcinoma - A five year single center experience
}

\author{
Sandeep Puvvada', Arvind Nayak K², Avinash B. Patil ${ }^{3}$, D. Ramesh ${ }^{4}$, Prasad Mylarappa ${ }^{5}$ \\ ${ }^{1}$ Assistant Professor, Urology, M.S. Ramaiah Hospital, Bangalore, Karnataka, India, ${ }^{2}$ Senior Resident, Urology, M.S. Ramaiah Hospital, \\ Bangalore, Karnataka, India, ${ }^{3}$ Senior Resident, Urology, M.S. Ramaiah Hospital, Bangalore, Karnataka, India, ${ }^{4}$ Senior Professor, Urology, M.S. \\ Ramaiah Hospital, Bangalore, Karnataka, India, ${ }^{5}$ Professor and HOD of Urology, M.S. Ramaiah Hospital, Bangalore, Karnataka, India
}

Aims and Objectives: To review a single centre experience in the evaluation, management and outcome of upper tract transitional cell carcinoma. Materials and Methods: We reviewed 18 cases over five years from January 2010 to October 2015 with a median follow up of 18 months. Patient characteristics including age, sex, symptoms and signs were reviewed. All patients were evaluated with ultrasound and contrast enhanced computerized tomography. Tumour details including location, laterality, grade and stage was noted based on pathological findings. Results: The mean age of the patients included was 57 years. Most common presentation was haematuria $(72 \%)$. Most common location of the tumours was renal pelvis $(50 \%)$, followed by ureter (39\%)and tumours in both renal pelvis and ureter in $11 \%$. Concomitant bladder involvement was seen in $17 \%$ of the patients. Nephroureterectomy with excision of bladder cuff was the most common surgery performed (78\%). $11 \%$ of the patients underwent renal sparing surgery and two other patients underwent nephroureterocystoprostatectomy. Morbidity rate was $22 \%$ and recurrence was seen in $16 \%$ of the patients. Conclusion: Transitional cell carcinoma of the upper tract is a rare tumour which is known for its multicentricity and recurrence. Nephroureterectomy with excision of bladder cuff has been the gold standard for the management, although endosurgical and tumour sparing surgery in selected cases have proven to be equally efficacious. Tumour grade and surgical procedure performed are independent risk factors for recurrence.

Key words: Renal tumors, Ureteric tumors, Transitional cell carcinoma,Upper tract transitional cell carcinoma, Recurrence

\section{Access this article online}

Website:

http://nepjol.info/index.php/AJMS DOI: http://dx.doi.org/10.3126/ ajms.v7i3.13894

E-ISSN: 2091-0576

P-ISSN: $2467-9100$

\section{INTRODUCTION}

Transitional cell carcinoma of the upper urinary tract is an uncommon disease encountered by the urologist, accounting for $5-10 \%$ of renal tumors and only $5-6 \%$ of urothelial tumors. Tumors of the ureter are an even rarer entity accounting for only $25 \%$ of the urothelial tumors. ${ }^{1}$ Upper tract transitional cell carcinoma is known for its multiplicity and recurrence. Nephroureterectomy with excision of ipsilateral bladder cuff has been considered to be the gold standard for the management of these tumors. However the advent of laparoscopy and advances in semirigid and flexible instrumentation has opened the door for conservative approaches to manage this tumor. The overall survival rate at five years is around $65 \% .^{2}$ We herein reviewed our five year experience in the evaluation management and outcome of 18 patients surgically managed for transitional cell carcinoma of the upper tract.

\section{MATERIALS AND METHODS}

We retrospectively reviewed patients who were surgically treated for upper tract transitional cell carcinoma at M S Ramaiah medical college from January 2010 to October 
2015. A total of 18 patients were traced using medical records. Clinical data was obtained reviewing patient files and operative logs. Patients were followed up with physical examination, cystoscopy and upper tract imaging every three moths for the first year and once in six months for the next two years. The median follow up was 18 months ranging from one to 60 months.

Patient characteristics including age, sex, symptoms and signs were reviewed. All patients were evaluated with ultrasound and contrast enhanced computerized tomography. A select few cases were further evaluated with Magnetic resonance Imaging and ureterorenoscopy. Tumor details including location, laterality, grade and stage was noted based on pathological findings. Operative logs were reviewed and the type of surgery, duration, intraoperative blood loss and complications were appraised. Postoperative complications and recurrence of tumor were assessed.

\section{RESULTS}

Patient characteristics and tumor details are described in Table 1. A total of 18 patients diagnosed with upper tract transitional cell carcinoma were included in our study. The mean age of the patients included was 57 years ranging from 41-70 years. Male to female ratio was 2:1.

Majority of the patients presented with hematuria (72\%). The other symptoms of presentation were flank pain $(22 \%)$, dysuria $(5 \%)$, and urinary tract infection $(11 \%)$. One patient presented with a palpable mass per abdomen. Urinary cytology was positive for malignant cells in four patients $(22 \%)$
Ultrasound was the initial investigating modality used. Contrast enhanced computerized tomography was the main investigating modality used to assess tumor location, invasion, lymph nodes and metastasis (Figure 1). In doubtful cases, magnetic resonance urography (3 cases) (Figure 2a)or ureteroscopy (2 cases)with brush biopsy (Figure 2b) was used to confirm the diagnosis.

Most common location of the tumors was the renal pelvis accounting for nearly $50 \%$ of the tumors. Transitional cell carcinoma of the ureter was seen in $39 \%$, one patient of which had tumor occupying the entire length of ureter (Figure 3). $11 \%$ of the tumors were present in both renal pelvis and ureter Concomitant bladder involvement was seen in three patients (Figure 4).

All patients were initially treated with surgery. Nephroureterectmy with removal of bladder cuff was the most common surgery performed accounting for nearly $78 \%$

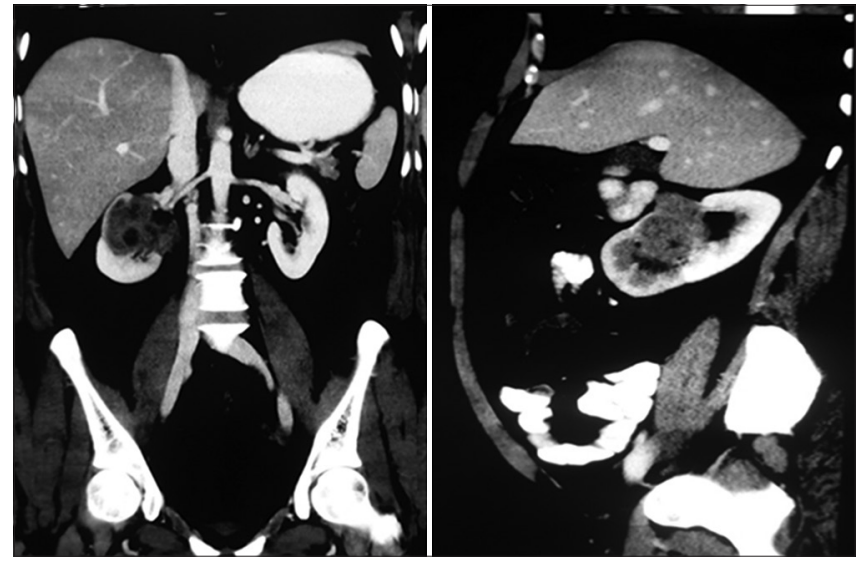

Figure 1: CT scan showing TCC of Right renal pelvis

\begin{tabular}{|c|c|c|c|c|c|}
\hline S. no & Age & Sex & Location & Surgery & Grade \\
\hline 1 & 54 & M & Renal pelvis & Nephroureterectomy & High \\
\hline 3 & 41 & $\mathrm{~F}$ & Renal pelvis & Nephrouretrectomy & Low \\
\hline 4 & 69 & M & Lower ureter & Distal ureterectomy+boari flap & High \\
\hline 5 & 61 & M & Lower ureter & Distal ureterectomy+reimplantation & Low \\
\hline 6 & 61 & M & Lower ureter+bladder & Nephroureterectomy+cystoprostatectomy & High \\
\hline 7 & 42 & $\mathrm{~F}$ & Renal pelvis & Nephroureterctomy & * \\
\hline 8 & 55 & $\mathrm{~F}$ & Renal pelvis & Nephroureterctomy & Low \\
\hline 9 & 49 & M & Renal pelvis and ureter & Nephroureterctomy & Low \\
\hline 10 & 57 & $\mathrm{~F}$ & Entire length of ureter & Nephroureterctomy & High \\
\hline 11 & 70 & M & Renal pelvis & Nephroureterctomy & Low \\
\hline 12 & 43 & M & Renal pelvis+ureter & Nephroureterctomy & Low \\
\hline 13 & 51 & M & Lower ureter+bladder & Nephroureterocystoprostatectomy & High \\
\hline 14 & 56 & M & Renal pelvis & Nephroureterctomy & High \\
\hline 16 & 59 & M & Renal pelvis & Nephroureterctomy & High \\
\hline 17 & 64 & $\mathrm{~F}$ & Mid ureter & Nephroureterctomy & Low \\
\hline 18 & 64 & M & Renal pelvis+bladder & Nephroureterectomy+TURBT & High \\
\hline
\end{tabular}




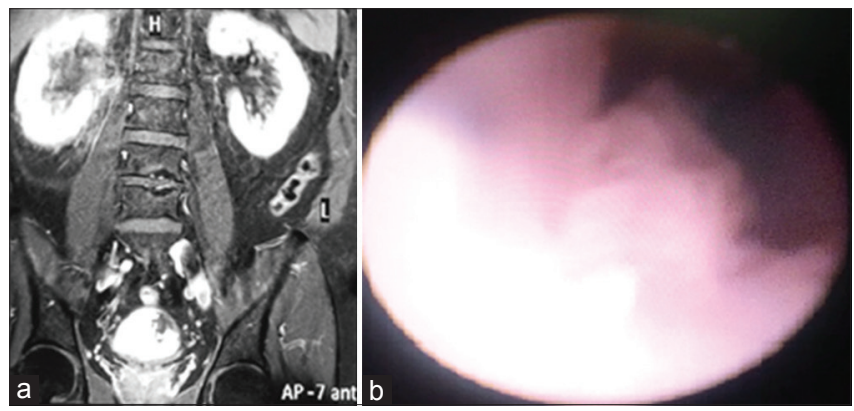

Figure 2: (a) MRI showing a right renal pelvic tumor with bladder tumor (b) ureteroscopy showing a ureteric TCC

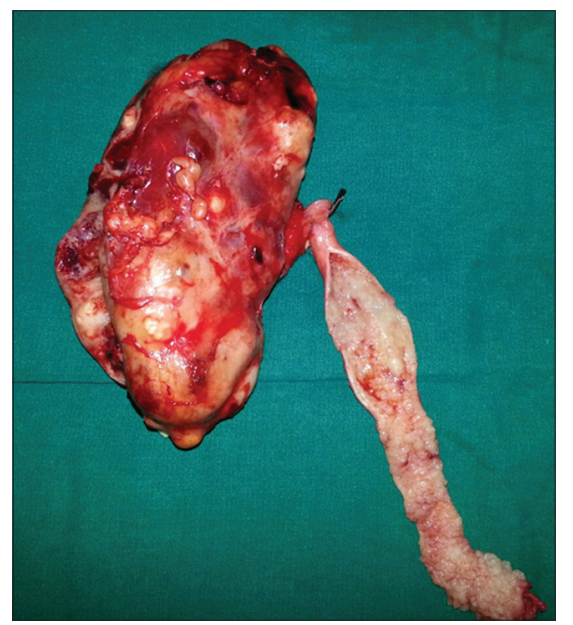

Figure 3: Tumor involving entire length of ureter

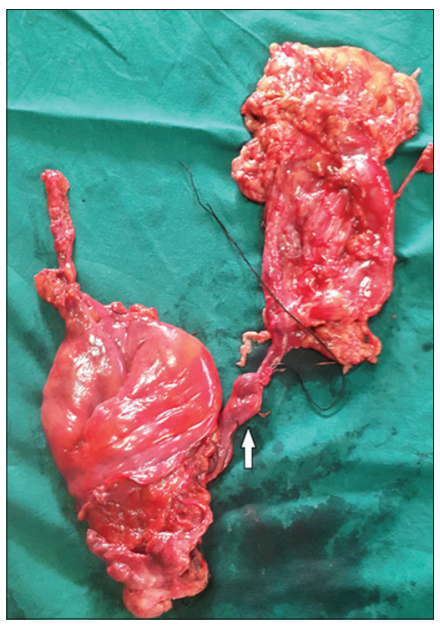

Figure 4 : Nephroureterocystoprostatectomy specimen with tumor involving bladder and lower ureter(arrow)

of the procedures. Patients with primary tumors in the renal pelvis and proximal ureter underwent this surgery. Eleven patients underwent laparoscopic nephroureterectomy along with bladder cuff excision through the incision used to retrieve the specimen. Three patients underwent open nephroureterectomy; these patients underwent transurethral resection of the intramural ureter. All patients underwent standard lymph node dissection.
Two patients who had primary tumor in the distal ureter underwent nephron sparing surgery in the form of distal ureterectomy. One of these patients needed a Boari flap to establish urinary tract continuity. Ureteric reimplantation was done in the other patient. Three patients who had concomitant bladder tumors were initially staged with Trans urethral resection of bladder tumor. Two of the patients, were diagnosed to have muscle invasive bladder tumor and underwent nephroureterocystoprostatectomy with orthotopic neobladder. The remaining patient, who had superficial bladder tumor, underwent nephroureterectomy along with transurethral resection of the intramural ureter for treatment of the primary transitional cell carcinoma of the renal pelvis.

Most of the tumors (50\%)were well differentiated low grade tumors, $44 \%$ were high grade. One patient was diagnosed to have a very rare sarcomatoid variant of transitional cell carcinoma. Lymph nodes were positive in three patients $(16 \%)$.

Recurrence was seen in three patients (16\%)and all patients had high grade tumors and one of these patients had undergone renal sparing surgery. Two patients had recurrence in the bladder and both patients underwent transurethral resection of bladder tumor. One patient who was diagnosed to have sarcomatoid variant of transitional cell carcinoma had recurrence in the retro peritoneum and liver and she was started on gemcitabine and cisplatin based chemotherapy.

Morbidity rate in our series was $22 \%$ with 2 patients developing minor surgical site infections. One patient who underwent nephroureterocystoprostatectomy, developed urine leak from the neobladder and was managed conservatively. One patient developed urosepsis and was managed with Intravenous meropenem. No cancer related deaths were observed during the course of follow up.

\section{DISCUSSION}

Transitional cell carcinoma of the upper tract is a fairly uncommon malignancy encountered in the urological practice accounting for $5-10 \%$ of renal tumors. ${ }^{1}$ The most common location of these tumors remains the renal pelvis. The incidence of transitional cell carcinoma in the ureter is scarce compared with the renal pelvis with a ratio of 1:3. ${ }^{3}$ Over the last 30 years, the incidence of renal pelvic tumors has remained fairly constant, however the incidence of ureteric tumors has been on the rise. ${ }^{1}$ Similarly in our series, nearly half the patients had renal pelvic transitional cell carcinoma and an additional $11 \%$ had renal pelvic and ureteric tumors. 
The peak incidence of tumors of the transitional cell tumors of upper tract is around the sixth and seventh decade of life and rarely occurs before the age of $40 .{ }^{1}$ Males are affected three times more than females. ${ }^{1} \mathrm{~A}$ familial incidence has been described in families with Balkan endemic nephropathy and is said to be 100-200 times more common in these patients. ${ }^{4}$ The other risk factors associated with upper tract transitional cell carcinoma are cigarette smoking, occupational factors analgesic abuse, coffee consumption, chronic infections and stones. ${ }^{5,6}$ Another risk factor associated with upper tract transitional tumors is the presence of bladder tumors. $1-4 \%$ of the upper tract urothelial tumors are associated with bladder urothelial tumors and this risk can raise up to $20 \%{ }^{7,8}$ Also approximately $30-75 \%$ of the upper tract transitional tumors have an associated bladder tumor. ${ }^{1,9}$ In our series concomitant bladder tumor was seen in $16 \%$ of the patients.

A distinguishing feature of these tumors is its multiplicity which is seen in $27-36 \%$ of the cases, ${ }^{1}$ however the incidence of bilateral tumors is low accounting for only $2-8 \%$ of the cases. ${ }^{1,10}$

The most common presenting symptom of these patients is microscopic or gross hematuria seen in $75 \%$ patients, followed by flank pain $(30 \%) .{ }^{1}$ Seventy-two percent of our patients presented with hematuria.

Ultrasound is usually the first investigating modality used and helps to distinguish between stone and tumors. Intravenous urography can appreciate filling defects in the ureter and pelvis in $50-70 \%$ of the tumors. ${ }^{1}$ Computerized tomography is a better imaging modality for determining local extent of primary tumor, invasion into renal parenchyma, assess lymph node involvement and metastasis. ${ }^{11}$ Magnetic resonance imaging has no added benefit over computerized tomography. ${ }^{1}$ Urinary cytology has a minimal role in the diagnosis, with a sensitivity of less than $50 \%$ and a specificity of $90 \% .^{12}$

Invasive diagnostic modalities include retrograde pyelography, cystoscopy, ureteroscopy and nephroscopy although the latter two have some therapeutic benefit. Retrograde pyelography has a sensitivity of about $70 \% .{ }^{12}$ Cystoscopy is usually recommended because of the high incidence of concomitant bladder tumors. Nephroscopy and ureteroscopy helps in evaluating the tumor and diagnoses with the help of cup or brush biopsy with a sensitivity of about $80 \%$ and specificity of $60 \% .{ }^{12}$ Transitional tumors of the upper tract are staged as UICC TNM classification of malignant tumours 2002 (Table 2)

Radical surgery in the form of nephroureterectomy with removal of bladder cuff has been considered the standard

\begin{tabular}{|c|c|}
\hline TX & Primary tumour cannot be assessed \\
\hline TO & No evidence of primary tumour \\
\hline Ta & Noninvasive papillary carcinoma \\
\hline Tis & Carcinoma in situ \\
\hline T1 & Tumour invades subepithelial connective tissue \\
\hline T2 & Tumour invades muscularis \\
\hline T3 & $\begin{array}{l}\text { (Renal pelvis) tumour invades beyond muscularis into } \\
\text { peripelvic fat or renal parenchyma; (ureter) tumour } \\
\text { invades beyond muscularis into periureteric fat }\end{array}$ \\
\hline T4 & $\begin{array}{l}\text { Tumour invades adjacent organs or through the kidney } \\
\text { into perinephric fat }\end{array}$ \\
\hline NX & Regional lymph nodes cannot be assessed \\
\hline No & No regional lymph node metastasis \\
\hline N1 & $\begin{array}{l}\text { Metastasis in a single lymph node } 2 \mathrm{~cm} \text { or less in } \\
\text { greatest dimension }\end{array}$ \\
\hline N2 & $\begin{array}{l}\text { Metastasis in a single lymph node (more than } 2 \mathrm{~cm} \text { but } \\
\text { not more than } 5 \mathrm{~cm} \text { ) in greatest dimension, or multiple } \\
\text { lymph nodes, none more than } 5 \mathrm{~cm} \text { in greatest dimension }\end{array}$ \\
\hline N3 & $\begin{array}{l}\text { Metastasis in lymph node more than } 5 \mathrm{~cm} \text { in } \\
\text { greatest dimension }\end{array}$ \\
\hline MX & Distant metastasis cannot be assessed \\
\hline MO & No distant metastasis \\
\hline M1 & Distant metastasis \\
\hline
\end{tabular}

of care for upper tract transitional cell carcinoma because of the high incidence of multicentricity and recurrence in the distal ureteral stump (16-58\%). ${ }^{1}$ Various techniques have been described for the removal of distal ureter and bladder cuff including two separate incisions, stripping, ${ }^{13}$ transurethral resection of intramural ureter ${ }^{14}$ and recently the laparoscopy. In our series, eleven patients underwent laparoscopic nephroureterectomy in whom bladder cuff excision was done through an incision used to deliver the specimen and 3 patients underwent transurethral resection of the intramural ureter along with open nephroureterectomy.

Since the last three decades conservative approaches to the management of upper tract has challenged the gold standard of nephroureterectomy in the management of upper tract transitional cell tumors. Renal sparing surgery can be performed in distal ureteric tumors, tumors in solitary kidney and bilateral tumors. ${ }^{1}$ This may not be possible in upper ureteric tumors because of the difficulty in bridging the ureteric gap. We managed to treat two cases of lower ureteric tumors with renal sparing surgery.

With the advancement in endourological technique, uereteroscopic and percutaneous techniques have been described using laser or electrosurgical techniques for the management of these tumors. ${ }^{15}$ Recurrence rates following minimally invasive surgery is high and is said to around $23-54 \% .{ }^{1}$ None of our patients were managed by endourological techniques.

The role of BCG instillation has been well established in the management of superficial bladder tumors; however 
the role of BCG is still in the management of upper tract transitional tumors is still in uncertain. Few reports of BCG instillation through nephrostomy tubes, ureteric catheters and by vesical urethral reflux through dubbel $\mathrm{J}$ catheters have been described. ${ }^{1,16}$ Radiotherapy has a limited role and is only considered in the local control of high grade high stage tumors and has no added survival benefit. ${ }^{17}$ The role of chemotherapy is still under trial and is mainly indicated in node positive and metastatic disease. One of our patient with sarcomatoid variant of transitional cell carcinoma received gemcitabine and cisplatin based chemotherapy

The tumor stage along with grade and the surgical procedure performed are important risk factors for recurrence. ${ }^{9}$ The five year disease free survival has been reported to be $100 \%$ for $\mathrm{Ta}, 91.7 \%$ for $\mathrm{T} 1$ and $72.6 \%$ for $\mathrm{T} 2$ and $40.5 \%$ for $\mathrm{T} 3$ tumors. ${ }^{1}$

\section{CONCLUSION}

Transitional cell carcinoma of the upper tract is a rare tumor which is known for its multicentricity and recurrence and should be suspected in elderly patients with hematuria and hydroureteronephrosis. Computerized tomography remains the most important diagnostic modality. Associated bladder lesions should always be ruled out. Nephroureterectomy with excision of bladder cuff has been the gold standard for the management of these tumors, although endosurgical and tumor sparing surgery in selected cases have proven to be equally efficacious. Tumor grade and surgical procedure performed are independent risk factors for recurrence. Strict follow up protocol has to be in place for all patients because of the high rate of recurrence.

\section{REFERENCES}

1. Oosterlinck W, Solsona E, van der Meijden APM, Sylvester R, Böhle A, Rintala E, et al. EAU guidelines on diagnosis and treatment of upper urinary tract transitional cell carcinoma. Eur Urol 2004;46(2):147-154.

2. Charbit L, Gendreau MC, Mee S and Cukier J. Tumors of the upper urinary tract: 10 years of experience. J Urol 1991;146(5):1243-1246.

3. Guinan P, Vogelzang NJ, Randazzo R, Sener S, Chmiel J,
Fremgen A, et al. Renal pelvic cancer: A review of 611 patients treated in Illinois 1975-1985. Cancer Incidence and End Results Committee. Urology 1992;40(5):393-399.

4. Petković SD. Epidemiology and treatment of renal pelvic and ureteral tumors. J Urol 1975;114(6):858-865.

5. Ross RK, Paganini-Hill A, Landolph J, Gerkins V and Henderson BE. Analgesics, cigarette smoking, and other risk factors for cancer of the renal pelvis and ureter. Cancer Res 1989;49(4):1045-1048.

6. Jensen OM, Knudsen JB, McLaughlin JK and Sørensen BL. The Copenhagen case-control study of renal pelvis and ureter cancer: Role of smoking and occupational exposures. Int J Cancer 1988;41(4):557-561.

7. Oldbring J, Glifberg I, Mikulowski P, Hellsten S. Carcinoma of the renal pelvis and ureter following bladder carcinoma: Frequency, risk factors and clinicopathological findings. J Urol 1989;141(6):1311-1313.

8. Solsona E, Iborra I, Ricós J V, Dumont R, Casanova JL, Calabuig C. Upper urinary tract involvement in patients with bladder carcinoma in situ (Tis): Its impact on management. Urology 1997;49(3):347-352.

9. Hall MC, Womack S, Sagalowsky Al, Carmody T, Erickstad MD, Roehrborn CG. Prognostic factors, recurrence, and survival in transitional cell carcinoma of the upper urinary tract: A 30-year experience in 252 patients. Urology 1998;52(4):594-601.

10. Racioppi M, D’Addessi A, Alcini A, Destito A, Alcini E. Clinical review of 100 consecutive surgically treated patients with upper urinary tract transitional tumours. Br J Urol 1997;80(5):707-711.

11. Scolieri MJ, Paik ML, Brown SL and Resnick MI. Limitations of computed tomography in the preoperative staging of upper tract urothelial carcinoma. Urology 2000;56(6):930-934.

12. Chen GL, El-Gabry EA and Bagley DH. Surveillance of upper urinary tract transitional cell carcinoma: The role of ureteroscopy, retrograde pyelography, cytology and urinalysis. J Urol 2000;164(6):1901-1904.

13. Roth $\mathrm{S}$, van Ahlen H, Semjonow A and Hertle L. Modified ureteral stripping as an alternative to open surgical ureterectomy. J Urol 1996;155(5):1568-1571.

14. Laguna MP, de la Rosette JJ. The endoscopic approach to the distal ureter in nephroureterectomy for upper urinary tract tumor. J Urol 2001;166(6):2017-2022.

15. Mills IW, Laniado ME and Patel A. The role of endoscopy in the management of patients with upper urinary tract transitional cell carcinoma. BJU Int 2001;87(2):150-162.

16. Nishino $\mathrm{Y}$, Yamamoto N, Komeda H, Takahashi $\mathrm{Y}$ and Deguchi $\mathrm{T}$. Bacillus Calmette-Guérin instillation treatment for carcinoma in situ of the upper urinary tract. BJU Int 2000;85(7):799-801.

17. Hall MC, Womack JS, Roehrborn CG, Carmody T, Sagalowsky AI. Advanced transitional cell carcinoma of the upper urinary tract: Patterns of failure, survival and impact of postoperative adjuvant radiotherapy. J Urol 1998;160(3 Pt 1):703-706.

\footnotetext{
Authors Contribution:

SP - Concept and design of the study, reviewed the literature, manuscript preparation andcritical revision of the manuscript; AN - Conceptualized study, literature search, statistically analyzed and interpreted, prepared firstdraft of manuscript and critical revision of the manuscript; ABP - Concept of study, collected data and review of study; DR - Conceptualized study, literature search, statistically analyzed and interpreted, prepared firstdraft of manuscript and critical revision of the manuscript; PM - Conceptualized study, literature search, statistically analyzed and interpreted, prepared firstdraft of manuscript and critical revision of the manuscript.
}

Source of Support: Nil. Conflict of Interest: None. 